\title{
Traducción/traición: cuerpos y nombres en las prácticas artísticas de Effy Beth
}

Pablo Farneda

Universidad Nacional de Entre Ríos-Facultad de Ciencias de la Educación- Centro de Investigaciones en Filosofía Política y Epistemología.

Fecha de recepción; 6 de marzo de 2018.

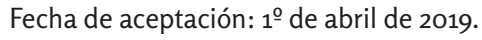

Traducir es instalarse en el espacio del equívoco y habitarlo. Eduardo Viveiros de Castro (2010: 76)

\section{Resumen}

En este trabajo se indaga en profundidad la video-performance Pequeña Elizabeth Mati (Little Mermaid doblado al castellano) (2012) de la artista trans feminista Elizabeth Chorubczyk, y la relación que establece esta con su obra. A partir de allí se exploran las operatorias de traducción que la artista activa en torno a su lengua madre y a su país de origen (Israel) y a los modos que su familia tiene de nombrarla cuando aún era llamada como un varón (Mati). Interesa indagar qué estrategias para hacerse un cuerpo se ponen en juego a partir de la distorsión, apropiación e intervención de las discursividades hegemónicas, cuando la traducción traiciona dichos mandatos y discursos.

Palabras clave:

Traducción, trans, naturaleza.

\begin{abstract}
This work investigates the video-performance Pequeña Elizabeth Mati (Little Mermaid doblado al castellano) (2012) of the trans feminist artist Elizabeth Chorubczyk, and its relation to the rest of her work. From there we explore a series of translation operations that the artist activates around the mother language and her country of origin (Israel), and over the ways that her family names her when she was considered still like a boy (Mati). Its result interesting investigates what strategies she invent to make her own body, from the distortion, appropriation and intervention over de hegemonic discursivities.
\end{abstract}

Translation, trans, nature. 


\section{Introducción}

En los últimos años, las prácticas artísticas trans se han convertido en un modo y un terreno de disputa por los sentidos en torno al género, al cuerpo y a las identidades para aquellas personas que rechazan el binomio de género masculino/femenino y las organizaciones que las representan. Estas prácticas han adquirido visibilidad en nuestra región en las obras de escritorxs ${ }^{1}$ y artistas como Naty Menstrual, Susy Shock, Camila Sosa Villada y Effy Beth en la Argentina; Pedro Lemebel e Hija de Perra en Chile; y Giuseppe Campuzano en Perú, entre otrxs. Estxs artistas han desplegado una serie de escrituras, performances y obras a través de las cuales expresan la complejidad de hacerse un cuerpo, un nombre, un territorio existencial y exponen allí estos procesos.

No se trata de que las obras sean modos de representación de dichas experiencias; antes bien, las prácticas artísticas devienen explícitamente performativas (Butler, 2006) y se convierten en un vector posibilitador, una expresión de fuerzas, un modo de creación vital. A lo largo de nuestra investigación hemos dado en llamarlas prácticas de sí (Farneda, 2016a), inscribiendo allí al menos dos sentidos: son prácticas de afirmación de una existencia singular lo que, siguiendo a Foucault $(2006,2008)$, podemos llamar modos y procesos de subjetivación. Por otro lado, dichos modos de afirmación se constituyen en una crítica activa a las formas naturalizadas de existencia, permitiendo comprender la creación como el único modo vital de la crítica (Nietzsche, 2016). En estos sentidos, frente a una cierta noción de arte político que consistiría en criticar una realidad o en representar las identidades subalternizadas, nos encontramos aquí con prácticas que disputan la propia lógica de la representación y no asumen la identidad o el campo social como algo fijo, transparente y posible de ser representado. ${ }^{2}$ Pensadas así, las artes devienen prácticas de hacerse, antes que modos de mostrarse.

La aparición de la expresión trans se ha constituido en un lente a través del cual leer estas complejidades. Prefijo de origen latino que significa, en principio, "más allá", "al otro lado" y "a través de", es crecientemente utilizado en las más diversas áreas de nuestro lenguaje para nombrar y dar cuenta de los movimientos, tránsitos y transformaciones. De la mano de los colectivos de disidencias sexuales y genéricas, tanto en Europa como en EE.UU., lo trans se ha instalado como un terreno de disputa por los sentidos y de cuestionamiento al binarismo. ${ }^{3}$ América Latina ha producido en estas décadas sus propias categorías, lógicas y modos de enunciación singular y colectiva, ${ }^{4}$ con lo cual los términos trans y queer no son recepcionados de manera sumisa en la región. ${ }^{5}$

1 Los problemas respecto del lenguaje, la escritura y los modos de nombrar son constantes y tensos a lo largo de este trabajo. La utilización en la escritura de los signos lingüísticos y tipográficos como la equis (x), el asterisco ("), la arroba (@) o la "e", se ha convertido en un recurso que vuelve evidente las marcas del poder en los usos de una lengua, que extraña esos usos y la materialidad del lenguaje en su condición androcéntrica. En tanto que alteran las asignaciones genéricas de las palabras aparecen como signos de-generados, produciendo una "molestia" en la lectura, una interferencia que considero productiva y prefiero conservar.

2 La tensión dentro del "arte político" y el cruce entre arte y política pueden ser abordados en la crítica contemporánea desde autorxs como Longoni (2007) y Speranza (2012). Ver también Foster (2003). 3 Es posible señalar aquí una extensa bibliografía en torno a las temáticas trans en el pensamiento y la investigación contemporáneos. Una referencia obligada se encuentra en los estudios queer, particularmente en las obras de autorxs como Butler $(2006,2007,2008)$, Halberstam $(2008,2018)$ y Preciado (2002, 2003, 2008, 2009), entre muchxs otrxs.

4 Interesa particularmente abordar desde la Argentina una serie de experiencias y reflexiones en torno a lo trans en la bibliografía que surge en gran medida a partir de escrituras de Ixs propixs protagonistas, activistas, integrantes de los colectivos y pensadorxs de las organizaciones travestis y trans. Se puede consultar: Fernández (2004); Berkins y Fernández (2005); Cabral (2006; 2009a y b); Maffía (2009 [2003]); Wayar (2009, 2018); Berkins (2013).

5 Algunas disputas en torno a los términos queer-cuir y sus apropiaciones sudacas-latinoamericanas pueden leerse en Kaminsky (2008), Rivas San Martín (2011) y Flores (2013). Respecto a la tensión trans/ travesti puede consultarse Berkins (2013). 
Lo trans abordado en tanto categoría resulta particularmente útil para interceptar por el medio los binomios de género y sexo, entre otros (varón-mujer, macho-hembra, masculino-femenino, e incluso naturaleza-cultura), dado que la expresión y la experiencia misma de lo trans cuestionan los puntos fijos naturalizados como "no trans" y los exponen como histórica y socialmente producidos. ${ }^{6}$ El desafío consiste entonces en dejar de preguntar qué es lo trans para asumirlo como territorio de pensamiento y de acción. Se trata de comenzar a investigar cuáles son los mecanismos y procesos sociales a través de los cuales ciertos cuerpos se naturalizan como correctos, normales, derechos y humanos o straight (Wittig, 2006 [1980]), o son leídos como cuerpos que importan mientras que otros son arrojados al lugar de lo abyecto (Butler, 2008). A partir de aquí es necesario indagar qué complejas relaciones mantienen estas delimitaciones entre sí, cuán necesaria es la abyección para fijar la normalidad. Desde una subversión política y epistémica de los colectivos y las perspectivas trans se trata entonces de preguntar qué es lo cis (lo considerado no trans), cómo funciona el binarismo y cómo se ha llegado a constituir un dispositivo como el de la heteronormatividad.

Pero también y crecientemente el prefijo se desmarca del ámbito sexo-genérico y comienza a afectar otras zonas de contacto y producción de la subjetividad y la sociabilidad, exponiendo a su vez los mestizajes y las hibridaciones étnicas, religiosas, culturales y de clases. Lxs artistas señaladxs más arriba se presentan como mucho más que personas transgénerxs y/o transexuales: se exponen produciendo y activando tránsitos que van desde la ciudad al campo y de vuelta, desde el conurbano al centro porteño, desde América hacia fuera, desde lo blanco a lo negro y de allí a lo indio, desde el cristianismo a la Pacha Mama trans y de vuelta a los sincretismos. En el campo del arte operan algo similar: desde los géneros consagrados a los géneros populares, desde lo conceptual a lo kitsch, desde la cumbia al canto de copla con caja. Zonas de extrañamiento, de traducciones de textos y transducciones de códigos, en donde lo trans desrealiza las fronteras fijas y estables.

En este artículo me centraré específicamente en algunas obras de la artista transfeminista conocida como Effy Beth, llamada Elizabeth Mía Chorubczyk. A través de la video-performance titulada Pequeña Elizabeth Mati (Little Mermaid doblado al castellano) (2012), y en el cruce con algunos de sus otros proyectos artísticos, será posible observar las zonas de traducción y confusión de los cuerpos y los nombres, el recurso a una serie de imágenes mitológicas como las sirenas para expresar el cuerpo y la generación de una zona intermedial donde los sentidos son trastocados y transformados en el acto de ser traducidos.

\section{Tradutore: traditore. La traición de Mía Chorubczyk}

Elizabeth Mía Chorubczyk (1988-2014), conocida como Effy Beth, fue una artista transfeminista de nacionalidad argentina/israelí. Vivió hasta los cinco años en Israel, y al comienzo de la Guerra del Golfo sus padres decidieron volver a Buenos Aires. ${ }^{7}$ En los últimos años, la obra de la artista ha tenido un impacto creciente en los campos tanto del arte contemporáneo como de los activismos queer, trans y de las desobediencias

6 Respecto de esta cuestión Butler señala: "Afirmar que todo género es como el travesti o está travestido sugiere que la "imitación” está en el corazón mismo del proyecto heterosexual y de sus binarismos de género, que el travestismo no es una imitación secundaria que supone un género anterior y original, sino que la heterosexualidad hegemónica misma es un esfuerzo constante y repetido de imitar sus propias idealizaciones" (2008: 184).

7 Elizabeth Mía Chorubczyk (Effy Beth) falleció el 26 de marzo de 2014 por decisión propia. El 13 de septiembre de 2015, su madre Dori Faigenbaum concedió una entrevista al programa radial "La Retaguardia", que fue transcrita y publicada en: http://www.laretaguardia.com.ar/2015/og/a-effy-no-lamato-la-sociedad-ella.html. Allí narra experiencias, relatos y reflexiona sobre la muerte de su hija. 
genérico-sexuales. A pesar de su pronto fallecimiento, Effy Beth produjo durante al menos ocho años una serie de proyectos de performances, obras conceptuales, intervenciones urbanas e intervenciones corporales como parte de su despliegue artístico y político. Participó activamente como performer en las marchas anuales del Orgullo LGBTIQ en la Ciudad de Buenos Aires, intervino en festivales y galerías de La Plata y Buenos Aires y supo inscribirse en una estela de artistas que cuestionan las categorías sexuales, genéricas, corporales e identitarias desde las prácticas artísticas, cuyos antecedentes recientes en la Argentina se remontan a la figura de Batato Barea, siendo además contemporánea de escritoras y performers como Susy Shock y Naty Menstrual.

Su nombre completo, elegido por ella, fue Elizabeth Mía Chorubczyk, y llegó a constar así en su Documento Nacional de Identidad, a pesar de varios conflictos que surgieron por problemas con su doble nacionalidad, incluso después de la aprobación de la Ley de Identidad de Género. De sus dos pasaportes, uno de ellos indicaba su género como masculino (el israelí) y otro como femenino (el argentino). Aunque declaraba preferir que su sexo no constara en ninguno de los dos, ella se sentía orgullosa de ese desfase.

A través de sus distintas obras de performance, foto y video-performance, blog-performance y textos, la artista intentaba plasmar no solo sus experiencias respecto al género, la sexualidad y la nacionalidad, que la colocaban y en las que ella se colocaba en una zona de indeterminación y extranjería, sino también una práctica que toma como superficie de expresión el cuerpo y los fluidos corporales, en la exploración de un cuerpo trans posible y habitable en tanto territorio singular-colectivo. ${ }^{8}$

Uno de sus proyectos artísticos más renombrados fue la performance en trece actos llamada Nunca serás mujer (2011). Allí la artista se extrajo medio litro de sangre y la dividió en trece partes para hacerse una menstruación con cada una de ellas: actos performáticos a través de los cuales fue narrando sus experiencias a lo largo del primer año de reasignación hormonal y la asunción de su identidad.?

A su vez, las imágenes y figuraciones ligadas a las sirenas encierran una potencia de expresión que la artista utilizó en su exploración acerca de los cuerpos liminales: cuerpos que se encuentran en zonas fronterizas, desapropiados de un territorio claro y definido. La sirena ha sido para Effy una imagen potente y pregnante: un terreno mítico que habilita la posibilidad de ser diferente y singular. Para ella se presenta incluso como un deseo y como uno de sus primeros recuerdos, atraviesa sus relatos desde su infancia en Israel y aparece repetidas veces en sus primeras escrituras. ${ }^{10}$

El 12 de agosto de 2012, Effy publica en su blog-arte una video-performance titulada Pequeña Elizabeth Mati (Little Mermaid doblado al castellano) (2012). ${ }^{11}$ En este trabajo edita, combina y produce un montaje de fragmentos de videos caseros en VHS realizados por su padre y familiares a lo largo de su primera infancia transcurrida en Israel en los años previos a la Guerra del Golfo.

8 Gran parte de su obra se encontró reunida por la propia artista en su página web hoy desactivada tras la finalización del plazo de propiedad del sitio web. Dora Faigenbaum y Matías Máximo han realizado un excelente trabajo al compilar la mayoría de las imágenes de la obra en un libro titulado Que el mundo tiemble. Cuerpo y performance en la obra de Effy Beth (2016), editado por la Universidad Nacional de La Plata y disponible en línea en: http://sedici.unlp.edu.ar/handle/10915/57876. Su obra puede consultarse también en un blog matriz en donde se habían reunido sus proyectos antes de tener su propia página web: http://tengoeffymia.blogspot.com.ar

9 El proyecto se encuentra relevado en el blog de la artista con el mismo nombre: www.nuncaserasmujer.blogspot.com. Un análisis exhaustivo de dicha obra se encuentra en Farneda (2016b).

10 Las figuraciones sirenaicas de Effy Beth se encuentran indagadas en Farneda (2018).

11 El video se encontró alojado en Youtube durante al menos seis años. Actualmente el link ya no está disponible debido a que "infringe las condiciones del servicio de Youtube". 
La video-performance muestra situaciones familiares y cotidianas, pero seleccionando significativamente los momentos cuando, a través de juegos y diálogos, se exponen las marcas del género sobre los cuerpos de la infancia, los llamados de atención, los señalamientos, desde los actos más inocentes como describir los juguetes hasta la mostración explícita de los genitales. ${ }^{12} \mathrm{Si}$ bien los diálogos se encuentran mayormente en castellano, algunas expresiones y frases aparecen en hebreo. El video está enteramente subtitulado en castellano y cuenta además con algunos carteles aclaratorios de situaciones.

El gesto performático que atraviesa el montaje consiste en el ejercicio de una tachadura $^{13}$ y allí reside la singularidad del trabajo: cada vez que es nombrada por sus padres y familiares con el nombre hebreo "Mati", la artista subtitula con su nombre "Elizabeth". A su vez, cambia los pronombres y el género de las palabras al femenino cuando hacen referencia a ella. A lo largo de todos los fragmentos las voces de sus familiares no aparecen silenciadas, se escuchan claramente, y sin embargo, Effy subtitula torciendo.

En algunos momentos su padre le solicita con reiteración que muestre el pene (el "pito"), la cola, que orine a cámara, que exponga su miembro, y él se muestra orgulloso de filmarlo y exhibirlo. Cada vez que Elizabeth es requerida para mostrar su pene ella subtitula "concha". Cada vez que su padre le habla de sus "bolas", ella subtitula "ovarios". Sin ocultar los rastros ni las marcas de quien fuera en su infancia, la artista produce una tachadura y una torsión sobre los nombres, el cuerpo y los mandatos: conserva y a la vez transforma los fragmentos de su biografía. Esta textualización torcida de escenas que aparecen registradas audiovisualmente produce una dislocación en la percepción de la imagen, en las representaciones de los cuerpos y de los nombres.

En el mismo video la artista también elige fragmentos en donde su madre filma su habitación de la infancia y describe sus juguetes: principalmente los automóviles, sin hacer mención a las muñecas que se observan al lado. Posteriormente, el video registra y expone la habitación que la familia tiene preparada en caso de que se desate la guerra, que opera a lo largo de la filmación como presencia fantasmática. Effy continúa luego seleccionando escenas de su infancia en las cuales es filmada jugando, cantando y probándose cosas. Cuando atina a llevarse un aro a la oreja para colocárselo, a una edad de alrededor de dos años y medio o tres, se escucha al padre que la reta detrás de cámara, ya que "los aritos no son para varones". Los últimos fragmentos son posteriores a la Guerra del Golfo, la muestran jugando en la nieve durante una de las pocas veces que nevó con tanta abundancia en Jerusalén, hecho ocurrido en 1992.

También la artista selecciona un fragmento en donde entona la canción de La Sirenita, en el momento en que Úrsula, la Bruja del Mar se lo solicita para poder llevarse su voz a cambio de convertirla en una chica. Todo esto está aclarado en los subtítulos. Al final del video aparece una leyenda que dice:

12 Algo así como una "marca generacional” emerge en los relatos de muchos varones nacidos entre las décadas de los setenta y de los noventa en cuanto a las fotografías y filmaciones de los padres (varones), exponiendo y/o explicitando los genitales masculinos de los hijos. Un famoso tipo de fotografías se multiplica en los álbumes de nuestras infancias: el niño en la bañadera, desnudo y sostenido por los brazos presuntamente de la madre, expuesto a la mirada de la cámara orgullosa, más que lúcida. Otra vez, y como lo analizara De Lauretis en profundidad, las tecnologías de la visualidad y de la imagen funcionan fundamentalmente como tecnologías del género.

13 En otra de sus obras Effy Beth ya había implementado el gesto performático de tachar, en el marco de la performance Nunca serás mujer (2011): tomando el DNI en donde consta su nombre masculino ella tachó con sangre ese nombre e inscribió, también con sangre, en su propio brazo, el nombre Elizabeth. La tachadura, como analizaré más adelante, no borra, ni invisibiliza ni hace desaparecer el nombre "oficial" del documento, sino que lo marca, lo superpone y también, de alguna manera, lo resalta. 
Actualidad: La pequeña Elizabeth Mati vive en Argentina enfrentando un absurdo juicio al Estado [para conseguir su identidad]. Los familiares aquí registrados la acompañan en su búsqueda de ser más humana. Artista conceptual y performer trans-feminista-queer...

A su vez, en la página del blog donde fue subido el video, la artista relata:

Video que recopila imágenes clave de mi infancia en Israel en torno a la Guerra del Golfo y mi cuerpo. Mi regalo hacia ustedes por el Día del Niño. Para que en este día reflexionemos sobre la sexualidad infantil, la identidad de género en la infancia, las presiones/mandatos sociales ejercidos desde antes de nacer, el maltrato y el abuso que no siempre tienen que ser carentes de afecto, perverso o violento para ser violencia.$^{14}$

El texto final incluido dentro del video expresa la actualidad de "Elizabeth Mati", en un gesto que, siendo el mismo gesto de toda la video-performance, construye un puente de relato, una continuidad y una contigüidad entre las imágenes y relatos de su infancia y su vida presente. El nombre Mati no aparece totalmente borrado o silenciado, sino tachado, superpuesto, entramado y extrañado con el nombre Elizabeth.

\section{La tachadura de Mati Chorubczyk}

El pensamiento contemporáneo, de la mano de Derrida (1997), ha explorado la noción y la experiencia de la tachadura en el lenguaje, como gesto de sustracción a la presencia o a cualquier origen fundante postulado como único, real y objetivo. Me interesa retomar estas nociones dado que se encuentran profundamente relacionadas con las experiencias de lo propio que implica hacerse un cuerpo, un nombre, un territorio, o sea, poner en marcha prácticas y políticas del sí mismx. Retomando a Derrida, Tortorelli (2014) desarrolla en su artículo "La violencia de lo vincular":

La propiedad del "sí mismo" se [nos] presenta como una inmediatez; es decir, como la inmediatez de una presencia consigo mismo. Tal presencia se presenta -valga la redundancia - sin fisura, sin alteridad, sin perturbación alguna y sin demora, sin dilación [...]. Lo que tal inmediatez, concordancia y adecuación deja impensado, sin embargo, es el desvío, el diferimiento, la demora que ese "con" del "con-sigo" mismo ya implica en su misma borradura. [...] Lo paradójico del "sí mismo", de la propiedad del "sí mismo" del deseo de adecuación "consigo mismo" es que, lejos de ser la inmediatez de una presencia en tanto concordancia de "uno" "consigo mismo", es radicalmente la borradura de un diferir, de un desvío, de un rodeo. Tal borradura no es sin violencia. (2014: 92)

A esta violencia Derrida (1997) la llama violencia de lo Uno, que se guarda de lo otro, se protege de lo otro que unx mismx es. Violentando esa demora y ese diferimiento de unx con sí mismx, lo Uno se guarda de la alteridad o la diferencia de sí (la diferencia consigo) que lo hace Uno. Derrida señala la dimensión temporal de este acontecimiento: "A la vez, al mismo tiempo, mas en un mismo tiempo disjunto, lo Uno olvida volver sobre sí mismo, guarda y borra el archivo de esta injusticia que él es. De esa violencia que hace" (1997: 44). El tiempo disjunto entonces es el tiempo que permanece como resto, en donde habita, valga la paradoja, una memoria olvidada y un archivo dañado. La memoria olvidada es la diferencia silenciada como condición para sostener una identidad una, igual a sí misma, y que acalla en su instauración la

14 La entrada del blog de la artista en donde estaba incrustado el video es: http://tengoeffymia.blogspot.com.ar/2012/o8/pequena-elizabeth-mati.html (última consulta: 13/12/2018). 
complejidad y la heterogeneidad que nos constituye. A lo largo de todo el trabajo realizado por Effy Beth es posible leer una traición a la lógica identitaria, presente a sí misma y pretendidamente coherente. La obra desrealiza cualquier naturalización de la constitución subjetiva genérica y corporal, haciéndola estallar en fragmentos (nombres, juegos, manos, alhajas, pitos, juguetes, conchas, máscaras de gas, cantos, voces, películas...) que se reúnen conservando su heterogeneidad, sin cuajar, un diferimiento que no logra ser silenciado.

Como afirma Tortorelli, "lo Uno es, en tanto, borradura de la diferencia. La posibilidad del 'sí mismo' lejos de ser una inmediatez, es un trabajo de apropiación" (2014: 93). Effy realiza dicho trabajo de apropiación del sí mismx exponiendo el juego complejo de las violencias que se ejercen, se producen, se naturalizan en la instauración de la coherencia, y las violencias necesarias para hacer estallar dichas naturalizaciones.

Lo que interesa fundamentalmente en esta obra es que la tachadura, a diferencia de la borradura, no elimina lo diferente, no oculta ni hace desaparecer la diferancia. ${ }^{15}$ La tachadura conserva un archivo torcido (queer/cuir), una memoria alterada. No pretende, sino que escapa a la completud y, como aclara Derrida, no niega, ni evita, no es el negativo sino el trazo (el tachado) que expresa la ausencia de un origen "verdadero", fijo, esencial, que des-objetiva el origen (1997: 54).

Es en este sentido que las tachaduras de Effy, tanto en su DNI como en su video-performance, no apuntan a restablecer un cierre del sí consigx mismx sino que conservan el grafo y el sonido de una diferencia que retorna indefectiblemente. Las voces de sus familiares en el video no aparecen silenciadas sino superpuestas (como el grafo del Estado en el DNI). Expresan la polifonía y la constitución coral del yo, compleja, transversal y torcida. El video no elimina, sino que expone la apertura constitutiva, que no sutura, que expresa la práctica de sí mismx como trabajo de apropiación y no como inmediatez. En el hiato se abren las preguntas: ¿no es todo nombre propio la tachadura del nombre que nos dieron en el gesto de hacerlo propio? ¿No es la discontinuidad del nombre propio la experiencia radical de tenerlo? Tal vez en la pregunta por él, por el modo en que ha llegado de lo expropio o de lo impuesto a lo propio, es que llegamos a tenerlo.

\section{Subversión perspectivista: desbaratar los conceptos}

En una segunda lectura esta video-performance puede ser abordada en su trabajo de traducción, más allá del sentido explorado hasta aquí que adquiere la tachadura. Para articular esta mirada me interesa recurrir a la noción antropológica de traducción desarrollada por Viveiros de Castro (2010), con el fin de explicitar los pasajes de códigos que se ponen en juego en el video, peron fundamentalmenten las contaminaciones de dichos códigos de semiotización nominal y corporal.

El proverbio italiano que ha motivado y atraviesa este trabajo, "traduttore, traditore", versa sobre la práctica de traducción como una práctica de traición. En torno a sus significados, los sentidos son también heterogéneos. Refieren a la imposibilidad de una traducción absoluta o literal, al peligro de pretenderla o de que un texto pierda su riqueza si es traducido literalmente. Al menos, en primera instancia se asume que una traducción traiciona indefectiblemente al texto de partida.

${ }_{15}$ El concepto de Derrida aquí es "différance" y ha sido traducido al castellano por "diferancia" para conservar la alteridad de la palabra. Estos desarrollos pueden leerse en Márgenes de la filosofía (2008). 
Según Viveiros de Castro, si traducir es siempre traicionar, una traducción digna de ese nombre es la que traiciona la lengua de llegada y no la de partida:

La buena traducción es la que consigue hacer que los conceptos extraños deformen y subviertan el dispositivo conceptual del traductor, para que la intentio del dispositivo original pueda expresarse en él y de este modo transformar la lengua de llegada. Traducción, traición, transformación. (2010: 73)

Así es que Effy Beth traduce el idioma del hebreo al español y transduce ${ }^{16}$ el código del género masculino al femenino, realizando incluso una traición por el medio, alterando todos los códigos lingüísticos y sexo-genéricos, abriendo a la exploración de una terra indómita. La traducción del género que produce la video-performance, descompone todo el sistema del género, impide un rápido amansamiento, o una reacomodación de los cuerpos y los términos, las palabras y las cosas. Perturba antes que aclara, disloca antes que relocaliza. La traducción de nene a nena transforma el término de llegada y fuerza la pregunta ¿pero entonces qué es una nena?, ¿qué creímos que era serlo?, ¿y qué otros modos de ser pueden inventarse?

Viveiros de Castro ha llamado a este proceso inversión perspectivista, operación gnoseológica y ontológica que se basa en una doctrina de lo equívoco, es decir, una alteridad referencial entre conceptos homónimos. ¿Qué significaría esta alteridad referencial entre conceptos homónimos? Todo concepto es la construcción de un término para alcanzar una generalidad que conciba (de allí concepto) o contenga varias particularidades. En sentido estricto para la filosofía clásica, un concepto no puede ser singular, sino abstracto, con capacidad para subsumir particularidades bajo una categorización general.

Sin embargo, cuando la performance de Effy dice "nene", "nena", "pito", "concha", difícilmente las palabras conserven su sentido convencional. Emerge una alteridad referencial para palabras que en principio se nos presentan como claras y distintas, pero que en la trama de la obra adquieren singularidad y extrañeza. La nena que es Effy en el video, ¿puede ser subsumida por el concepto de nena que nuestro sistema categorial binario determina? Cuando el video dice "nena", no dice lo que el concepto habitual de nena pretende representar. Aunque los conceptos sean homónimos expresan una alteridad referencial que da cuenta del equívoco fundamental que todo lenguaje guarda en el corazón mismo de su proyecto de nombrar.

\section{Las fuerzas de la naturaleza desatadas}

La antropología perspectivista amazónica ${ }^{17}$ construye su propio concepto de perspectivismo retomándolo de un pensamiento que es propio de los amazónicos, quienes afirman que no es la cultura, o el llamado punto de vista cultural, lo que nos brinda la singularidad radical de la perspectiva sino el punto de vista corporal. Son los cuerpos y

16 Se define como transducción el proceso por el cual en la traducción de un tipo de señal o energía a otra se da una transformación de naturaleza de dicha señal o energía. El término proviene originalmente de las ciencias biológicas para designar transducciones de códigos genéticos entre bacterias y afectaciones de códigos entre distintas especies a través de virus, pero luego ha sido incorporado al mundo de las ciencias humanas dentro de la teoría literaria. Me interesa aquí rescatar su sentido menos metafórico y su dimensión matérica, transformacional del sistema energético, tal cual la elabora y desarrolla Simondon (2015) en el marco de su teoría sobre la individuación.

17 Algunxs investigadorxs que pueden inscribirse dentro del campo de la antropología perspectivista amazónica son Viveiros de Castro y Stolze Lima en Brasil, Cohn en la selva ecuatoriana, y Narby, con sus trabajos en el amazonas peruano, entre otrxs, quienes han desarrollado sus investigaciones etnográficas en el Amazonas, siguiendo la estela estructuralista y posestructuralista del propio LeviStrauss en el mismo territorio. 
no las "mentes" o "culturas", los que producen radicalmente el modo de ver, percibir y sentir el mundo. A partir de estas nociones, Viveiros de Castro deduce lo que se vuelve fundamental para la antropología contemporánea: una traducción del concepto de traducción de otras culturas y, específicamente en este caso, de aquello que implica "traducir" para el pensamiento amazónico. Traducir es asumir la alteridad referencial que se produce, a partir de la singularidad corporal, entre nociones y conceptos que en principio y demasiado tranquilamente a veces, asumimos como inteligibles desde una mirada discursiva y culturalista.

En el caso de la traducción perspectivista de Effy Beth las nociones de "nena", de "mujer", de "vagina", que ella opera, no se refieren al concepto de "nena", "mujer" y "vagina" que nuestras perspectivas - tanto culturalistas como biologicistas-construyen de esos mismos términos. No traduce de nene a nena, ni de pene a vagina, ni de varón a mujer; traduce desrealizando los conceptos de nena, de mujer y de vagina, al introducir en esa dualidad una multiplicación que extraña la noción de partida: de un nene-nene (lo que el padre nombra, llama, muestra, exhibe, expone) a un nene-nena (un Mati sirenita), que busca y llega a ser nena-nena (Elizabeth Mía Chorubczyk), para reencontrar su nena-nene de la infancia (Elizabeth-Mati). Los dos términos se han transformado al menos en cuatro: o sea, en una multiplicidad. Al hacerlo, la traducción desmantela la lógica binaria, se vuelve equívoca y múltiple, inventa otro modo de ser nene, tanto como de ser nena, más allá de los horizontes de imaginación cultural. Y, otra vez, esta operación de traducción y de producción de perspectiva es realizada a partir de la singularidad corporal de Elizabeth-Mati, experimentada a través de un vector teratológico: la imagen de la sirena, las figuraciones sirenaicas.

El ultimo fragmento del video abordado muestra a Elizabeth Mati todavía viviendo en Israel, en casa de su abuela, a la edad de cuatro años y medio. Mati es filmado por su mamá mientras ella le pregunta si quiere cantar como "la sirenita", refiriéndose al filme de Walt Disney. En dicha película el personaje de la sirenita, llamado Ariel (nombre genéricamente indefinido también), realiza un pacto con Úrsula, la bruja del mar, la única que puede convertirla en una "verdadera" mujer, con piernas (y vagina, cosa que el filme no aclara, porque aparentemente no es necesario), para que pueda reencontrarse con el Príncipe y enamorarlo. A cambio, Ariel debe entregar su voz a la bruja del mar, en una escena en donde tararea una melodía para que la bruja la capture. Frente a la invitación de su mamá a cantar, Elizabeth-Mati entona la melodía que corresponde a dicha escena. Esta información aparece aclarada también en los subtítulos.

Los relatos de Chorubczyk enlazan y se apropian de las figuraciones sirenaicas, esas que encuentra en la cultura de masas y que le sirven a la artista para tramitar, negociar sentidos, abordar experiencias, nombrar y pensar la posibilidad de un cuerpo deseable. El rasgo de la voz que la película pone de relieve no es indiferente dado que es allí también, y no en la apariencia visual, donde se operan procesos de normalización, corrección y ortopedia de los géneros y las identidades. La propia voz puede devenir en el elemento de mayor exposición, el punto de inflexión del simulacro de la imagen. La voz expone al cuerpo y lo abre al encuentro de una manera diferente a como lo hace la mirada. En este caso la sirenita negocia la posibilidad de ser una mujer "verdadera" a cambio de su voz y claro está, a cambio de la posibilidad de decir. Monstruoso es, más que los cuerpos anormales, el proceso de normalización por el que los cuerpos pasan para volverse "naturales": fundamentalmente, deben ser silenciados.

En la exposición y parodización de estos mismos procesos, Effy publica una serie de cómics en su página privada de Facebook ${ }^{18}$ en donde aparece, otra vez, la Sirenita de Disney. Luego de haber conseguido sus piernas para poder ir en busca de su príncipe 18 Material parcialmente incluido en su blog. 
Eric, pero con un pene que sobresale del agua, el pelícano de la película le dice: “¿Así que la Bruja del mar te quitó la voz para que Eric no se diera cuenta de que naciste sin vagina? Bueno, ahora habrá que taparte con algo, ¿no?".

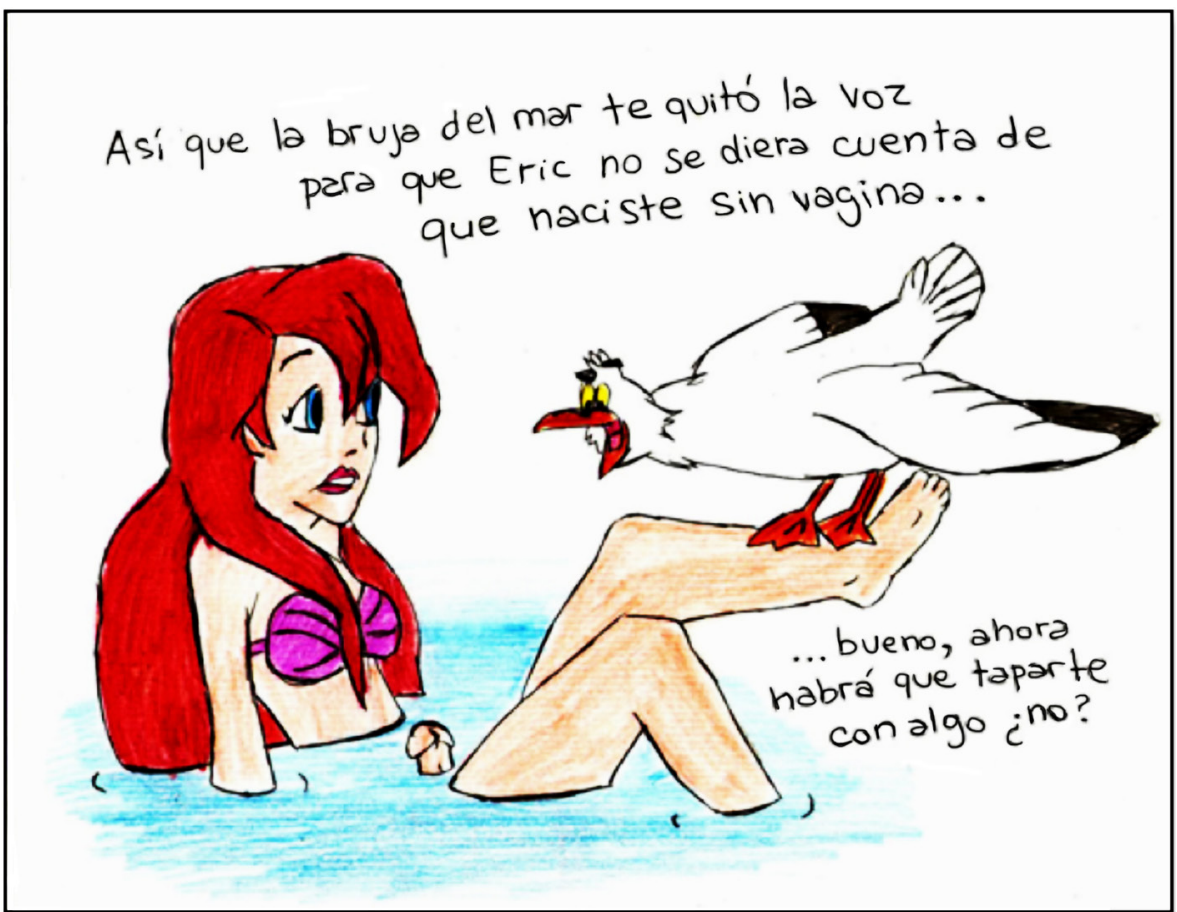

Figura $1^{19}$

En este cómic, Effy deja de presuponer que además de piernas la bruja le otorgue a Ariel una vagina, produce incluso una variación en esa presuposición naturalizada: estrictamente hablando nada impide imaginar que Úrsula haya podido darle un pene en vez de vagina.

El cuerpo entonces es contínuamente el enigma de la normalidad, aquello que una y otra vez escapa a la imagen idealizada: sin voz, pero con piernas. Con piernas, pero sin vagina, con vagina, pero sin voz... El "sexo" y el cuerpo no se presentan como un sustrato natural sobre los cuales los géneros y las identidades se dan culturalmente o se construyen subjetiva o socialmente. Más bien, el sexo y el cuerpo son el efecto de una continua modelización, una performatividad insistente y escultórica que nuestras prácticas y discursos realizan con ellos.

Nos encontramos aquí nuevamente con un problema de traducción en el sentido antes mencionado: no se registra una traducción de sentidos culturales, ni un problema de comunicación o significación, sino una traición que va de la cultura a la naturaleza: el punto de vista que permite a Effy interpelar el sentido sobre lo normal y lo patológico, el cuerpo humano y el monstruoso, el lugar del varón y de la mujer, es el punto de vista que emerge a partir de la singularidad de su cuerpo. ¿Pero qué naturaleza es esa que las obras de Effy Beth activan, movilizan y conceptualizan?, ¿y cuáles son sus fuerzas?

Claramente la definición misma de lo que se recorta como naturaleza es uno de los campos de disputa más importantes en la historia de la filosofía y, particularmente, 19 Foto subida a la página personal de Facebook de Elizabeth Chorubczyk. 
del pensamiento actual. ${ }^{20}$ Tal vez los feminismos contemporáneos, de la mano de muchas otras perspectivas no occidentales sobre la propia noción de naturaleza, sean las corrientes de pensamiento que han asestado una herida de muerte al esencialismo antropocéntrico y logocéntrico. La noción que introduzco y formulo aquí puede nombrarse como la producción de una naturaleza contra-natura en el modo particular en que el pensamiento de Deleuze retoma la noción de Spinoza, para producir y activar una filosofía de la naturaleza naturante: más allá de las "leyes" de la naturaleza (como se ha hablado históricamente de las leyes de la física e incluso en un lenguaje contemporáneo, de las estadísticas de la biología), se encuentran y emergen contínuamente las creaciones suigeneris que se producen en la singularidad de los cuerpos y los procesos matéricos. La natura naturans en la lectura spinozista de Deleuze es aquella causa sui, infinita y capaz de producir infinitas variaciones más allá de lo sabido y lo conocido, de lo medible, cuantificable y normalizable.

Naturaleza contra-natura puede llamarse a aquellas fuerzas que invisten el campo vital (de las sociedades humanas y de los ecosistemas en general), que hacen estallar los límites de lo reconocible, que desbaratan los procesos de estabilización, que producen variación, biodiversidad, deriva, mutación, en fin, condiciones de expansión de la vida. Que la naturaleza actúe contra sí misma (contra sus cristalizaciones y fijaciones) implica que actúa abriendo nuevas potencias y condiciones vitales, nuevos modos de ser: diferencia como condición de la multiplicidad.

Las distribuciones de lo natural y lo cultural quedan así trastocadas frente a estos devenires, estos procesos que acontecen por el medio, atravesando e interpelando los cuerpos. La traducción que Effy realiza entonces no performa un cuerpo que va, culturalmente hablando, de lo masculino a lo femenino sino a costa de hacer devenir lo masculino y lo femenino en otras cosas, en nuevos modos, y mediante la traición a los parámetros de normalidad.

La equivocidad, al contrario de cualquier perspectiva que la tomaría como un impedimento o una dificultad del proyecto de traducción, es la condición misma de posibilidad de la traducción. Por eso tal vez es pertinente retomar aquí la expresión utilizada en el epígrafe y ampliarla:

Traducir es instalarse en el espacio del equívoco y habitarlo. No para deshacerlo, porque eso supondría que nunca ha existido, sino todo lo contrario, para destacarlo o potenciarlo, es decir, para abrir y ensanchar el espacio que imaginábamos que no existía entre los "lenguajes" en contacto... El equívoco no es lo que impide la relación sino lo que la funda y la impulsa: una diferencia de perspectiva. Traducir es presumir que hay, desde siempre y para siempre, un equívoco; es comunicar por la diferencia, en lugar de guardar al Otro en silencio presumiendo una univocalidad originaria y una redundancia última —una semejanza esencial—entre lo que él era y lo que nosotros "estábamos diciendo". (Viveiros de Castro, 2010: 76)

En definitiva, y para (im)precisar más aún la noción de traducción, es posible afirmar que se encuentra en el corazón mismo de toda experiencia de comunicación: todo acto de lectura es una acción de traducir y de producir ajustes entre términos de partida y de llegada. Otra imagen de la artista dentro de su serie de cómics Transita Rápido $(2012)^{21}$ nos brinda la posibilidad de reflexionar sobre dichos procesos.

20 La disputa es larga y muy heterogénea pero, por nombrar algunos autores europeos, para observar cómo esta disputa cala en el corazón mismo del proyecto intelectual eurocéntrico, ver Serres (2004); Latour (2007, 2013); Jullien (2010) y Sloterdijk (2011).

21 En línea en: http://transitarapido.blogspot.com.ar 


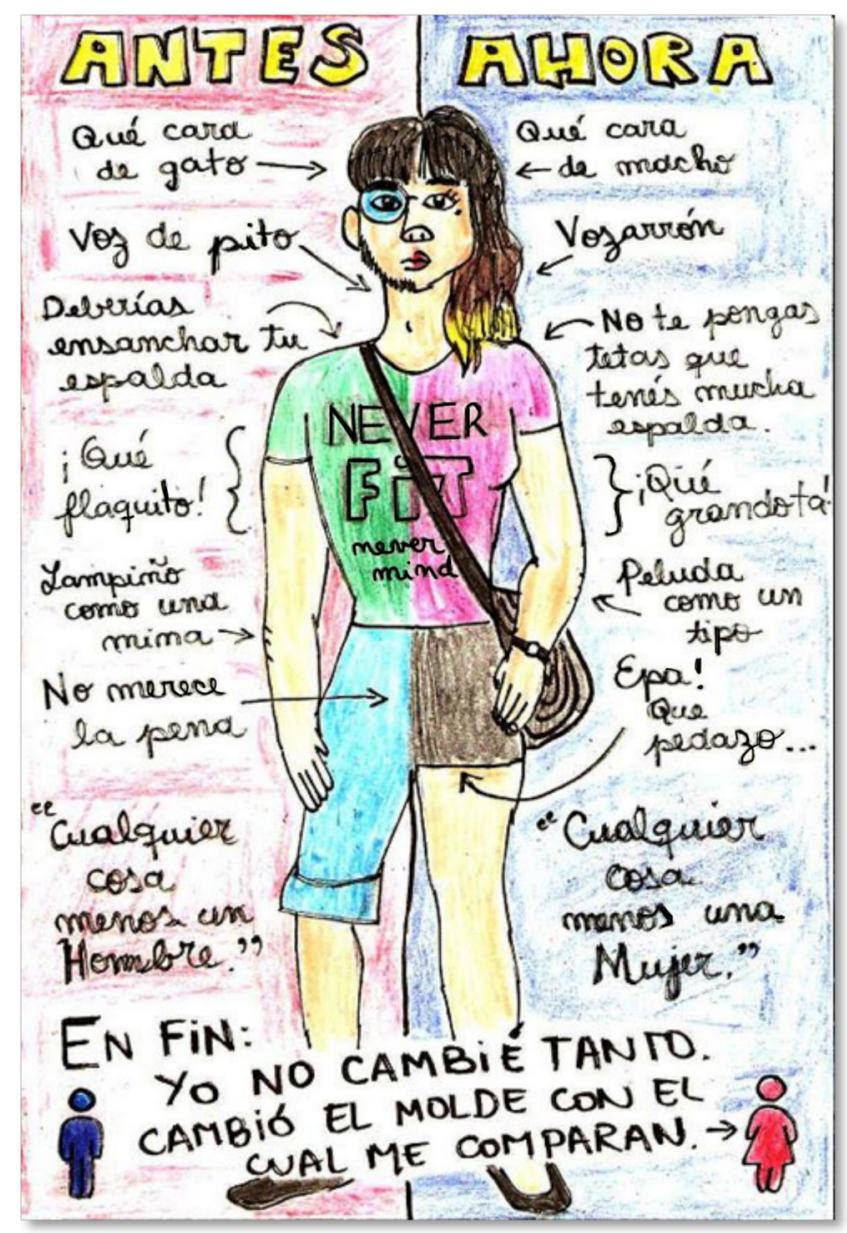

Figura $2 .{ }^{22}$

Allí puede verse también la operación de lectura que recae sobre los cuerpos travestis, trans, ambiguos, andróginos o simplemente "poco claros y distintos", demasiado feminizados o muy poco, excesivamente masculinizados y todo el tiempo sobreinterpretados. Traducciones literales que fallan y hacen fallar la vida en el peor sentido. Así, la imagen da cuenta de que toda operación de traducción es realizada siempre desde una episteme (Foucault, 2005), desde una grilla de inteligibilidad, desde conceptos, parámetros y categorías sociales e históricamente construidos.

\section{Conclusiones}

A lo largo de este artículo hemos recorrido una serie de lecturas posibles en torno a la video-performance Pequeña Elizabeth Mati (Little Mermaid doblado al castellano) (2012) de Elizabeth Chorubczyk. La noción misma de video-performance se propone dar cuenta de una operación continua y procesual de hacerse y deshacerse. El video no es realizado en tanto filme, película o cortometraje, sino en tanto acción de desmarcarse y reinventarse y, por esto mismo, es abordado desde esta dimensión performática (la acción de la artista) y performativa (los efectos del proceso).

Ha sido fundamental observar qué imaginarios y operaciones emergen en esta obra y se encuentran a lo largo de otras producciones de la artista: una posición de frontera, 22 Effy Beth. Cómic núm. 15, Sobre moldes, de la serie “Transita Rápido” (2012). 
la superposición de tradiciones de la historia del arte con la cultura de masas, las prácticas de traducción, la utilización de las figuraciones sirenaicas. Me ha interesado argumentar que en la estela de artistas travestis y trans como Susy Shock y Naty Menstrual, cuyas obras literarias, musicales y de performances exploran las prácticas de hacerse un cuerpo, un nombre y un territorio existencial, la obra de Chorubczyk produce también una zona liminal, un espacio intermedial a partir de un devenir continuo de las categorías sexuales y genéricas que organizan los cuerpos.

Esta posición de frontera es un territorio desde el cual negociar los tránsitos de sentidos y cuerpos que acontecen entre los espacios sociales legitimados, reconocidos, naturalizados, y un afuera indómito en donde los cuerpos y las subjetividades quedan relegados como abyectos (Butler, 2008), monstruosos o simplemente invisibles.

Las zonas de creación de espacios intermediales, e incluso, tomando prestado el concepto que Winnicott (1987) desarrollara para pensar la producción inter y transubjetiva como espacios transicionales, son territorios de invención de mundo y de producción de singularidad. En ausencia de planos complejos de tramitación del cuerpo con las fuerzas del mundo, el arte deviene en territorio de exploración y experimentación. Para estas artistas la dimensión política del arte emerge en cada práctica de creación y cada vez necesita ser relanzada, como una apuesta.

Fundamentalmente además, el trabajo de análisis realizado aquí se ha propuesto dar cuenta de la dimensión procesual de la traducción. Antes que un acto de traducir encontramos en la obra analizada de Effy Beth un proceso y un devenir, en donde los términos de partida y de llegada son traicionados como condición para producir una vida singular que valga la pena ser vivida. 


\section{Q Bibliografía}

»Berkins, L. (2013). Los existenciarios trans. En Fernández, A. M. y Siqueira Peres, W. (eds.). La diferencia desquiciada. Géneros y diversidades sexuales. Buenos Aires, Biblos.

» Berkins, L. y Fernández J. (2005). La gesta del nombre propio. Informe sobre la situación de la comunidad travesti en la Argentina. Buenos Aires, Madres de Plaza de Mayo.

» Butler, J. (2006 [2004]). Deshacer el género. Buenos Aires, Paidós.

》------- (2007 [1990]). El género en disputa. Buenos Aires, Paidós.

»------ (2008 [1993]). Cuerpos que importan. Sobre los límites materiales y discursivos del $\bigotimes$ sexo®. Buenos Aires, Paidós.

»Cabral, M. y Maffía, D. (2009). Los sexos ¿son o se hacen?. En Maffía, D. (comp.). Sexualidades migrantes. Género y transgénero [2003]. Buenos Aires, Mujeres Editoras.

"Cabral, M. y Maffía, D. (2009). Los sexos ¿son o se hacen?“. En Maffía, D. (comp.). Sexualidades migrantes. Género y transgénero. Buenos Aires, Mujeres Editoras.

"Cabral, M. (2006). La paradoja transgénero“. En Ciudadanía Sexual. Boletín núm. 18. En línea: http://www.ciudadaniasexual.org/boletin/b18/articulos.htm

»Cabral, M. (2009a). Interdicciones. Escrituras de la intersexualidad en castellano. Córdoba, Anarrés.

»---- (2009b). Pensar la intersexualidad, hoy“. En Maffía, D. (comp.). Sexualidades migrantes. Género y transgénero. Buenos Aires, Mujeres Editoras.

»Chorubczyk, E. (2011). Nunca serás mujer. Proyecto performático registrado en el blog: http://nuncaserasmujer.blogspot.com (última visita: 02-07-20).

»-------- (2012). Pequeña Elizabeth Mati (Little Mermaid doblado al castellano). Video-performance (no disponible actualmente en la web)

»Chorubczyk, E. (2011). Nunca serás mujer.

"-------- (2012). Pequeña Elizabeth Mati (Little Mermaid doblado al castellano).

"De Lauretis, T. (1989). Technologies of Gender. Essays on Theory, Film and Fiction. Londres, Macmillan Press. .

»Deleuze, G. (2008). En medio de Spinoza. Buenos Aires, Cactus.

»Deleuze, G. y Guattari, F. (2007 [1980]). Mil mesetas. Capitalismo y esquizofrenia. Valencia, Pre-Textos.

»Derrida, J. (1997). Mal de archivo. Una impresión freudiana. Madrid, Trotta.

»------ (2008). Márgenes de la filosofía. Madrid, Cátedra.

»Faingenbaum, D. y Máximo, M. (2016). Que el mundo tiemble: cuerpo y performance en la obra de Effy Beth. La Plata, EDULP.

» Farneda, P. (2016a). Prácticas de sí. Subjetividades contemporáneas en las prácticas artísticas trans actuales en Buenos Aires. Tesis de Doctorado, Teoría e Historia de las Artes, Facultad de Filosofía y Letras, UBA. Defendida el 11/03/2016. 
»------- (2016b). Prácticas artísticas trans: estrategias ex-céntricas para hacerse un cuerpo propio. En Versión. Estudios de comunicación y Política, núm. 37/ octubre-abril, pp. 155-171. En línea; http://version.xoc.uam.mx

》 ------- (2018). Teratologías: figuraciones sirenaicas en la obra de Elizabeth Chorubczyk (Effy Beth). En Revista Aisthesis, núm. 64. Santiago de Chile, Pontificia Universidad Católica.

» Fernández, J. (2004). Cuerpos desobedientes. Travestismo e identidad de género. Buenos Aires, Edhasa.

»Flores, V. (2013). Interrupciones. Ensayos de poética activista. Neuquén, La Mondonga Dark.

» Foster, H. (2003). Recodificaciones: hacia una noción de lo político en el arte contemporáneo. En Blanco, P.; Carrillo, J.; Claramonte, J. y Expósito, M. (eds.). Modos de hacer. Arte crítico, esfera pública y acción directa. Salamanca, Ediciones Universidad de Salamanca.

"Foucault, M. (2005). Las palabras y las cosas. Una arqueología de las ciencias humanas. Buenos Aires, Siglo XXI.

"------- (2006). La hermenéutica del sujeto. Buenos Aires, FCE.

»----- (2008). Tecnologías del yo. Buenos Aires, Paidós.

» Halberstam, J. (2008). Masculinidad femenina. Madrid, Egales.

》------ (2018). El arte queer del fracaso. Barcelona, Egales.

» Jullien, François (2010). Las transformaciones silenciosas. Barcelona, Bellaterra.

"Kaminsky, A. (2008). Hacia un verbo queer. En Revista Iberoamericana, vol. LXXIV, núm. 225, octubre-diciembre.

" Latour, Bruno (2007). Nunca fuimos modernos. Ensayo de antropología simétrica. Buenos Aires, Siglo XXI.

»Latour, Bruno (2013). Políticas de la naturaleza. Barcelona, RBA Libros.

"Longoni, A. (2007). Otros inicios del conceptualismo (argentino y latinoamericano). En el blog: Arte Nuevo (última consulta: 11-03-15). En línea: http://artenuevo.blogspot.com.ar/2007/o5/otros-inicios-del-conceptualismo.html

»Maffía, D. (comp.) (2009 [2003]). Sexualidades migrantes. Género y transgénero. Buenos Aires, Mujeres Editoras.

» Nietzsche, F. (2016 [1883]). Así habló Zaratrustra. En Obras completas, vol. IV. Madrid, Tecnos.

»Preciado, B. (2002). Manifiesto contra-sexual. Prácticas subversivas de identidad sexual. Madrid, Opera Prima.

"------ (2003) Multitudes queer. Notas de una política para "los anormales". En Revista Multitudes, núm. 12. En línea: http://www.multitudes.net/Multitudes-queer/

»------- (2008). Testo Yonqui. Madrid, Espasa.

»------ (2009). Queer. Historia de una palabra. En Revista/Blog Parole de queer, abril-junio. En línea: http://paroledequeer.blogspot.com.ar/2012/o4/queerhistoria-de-una-palabra-por.html (última consulta: 14/08/15).

"Rivas San Martín, F. (2011). Diga "queer" con la lengua afuera: Sobre las confusiones del debate latinoamericano. En CUDS (Segundo Circuito de Disidencia Sexual). Por un feminismo sin mujeres. Santiago de Chile, Territorios Sexuales Ediciones. 
"Simondon, G. (2009). La Individuación. A la luz de las nociones de forma e información. Buenos Aires, Cactus/La Cebra.

» Serres, Michel (2004). El contrato natural. Valencia, Pre-Textos.

»Sloterdijk, P. (2011). Sin salvación. Tras las huellas de Heidegger. Madrid, Akal.

"Speranza, G. (2012). Atlas portátil de América Latina. Arte y ficciones errantes. Buenos Aires, Anagrama.

»Tortorelli, A. (2014). La violencia de lo vincular. En Altobelli, H.; Farneda, P. y Grandal, L. Entreveros y afinidades. Clínica psicoanalítica, ética y nuevos dispositivos. Paraná, Fundación La Hendija.

"Viveiros de Castro, E. (2010). Metafísicas caníbales. Líneas de antropología postestructural. Buenos Aires, Katz.

"Wayar, M. (2009). Editorial. En El Teje. Periódico travesti latinoamericano, año 2, núm. 4, junio. Buenos Aires.

»------- (2018). Travesti. Una teoría lo suficientemente buena. Buenos Aires, Muchas Nueces.

»Winnicott, D. (1987). Realidad y juego. Barcelona, Gedisa.

»Wittig, M. (2006 [1980]). El pensamiento heterosexual y otros ensayos. Madrid, Egales. 